\title{
Case Report \\ Transient Pseudohypoaldosteronism due to Urinary Tract Infection in Infancy: A Report of 4 Cases
}

\author{
Radha Nandagopal, ${ }^{1}$ Priya Vaidyanathan, ${ }^{2}$ and Paul Kaplowitz ${ }^{2}$ \\ ${ }^{1}$ Inter-Institute Pediatric Endocrinology Training Program, Eunice Kennedy Shriver National Institute of Child Health and \\ Human Development, National Institutes of Health, Bethesda, MD 20892, USA \\ ${ }^{2}$ Department of Endocrinology, Children's National Medical Center, Washington, DC 20010, USA
}

Correspondence should be addressed to Paul Kaplowitz,pkaplowi@cnmc.org

Received 5 December 2008; Revised 10 March 2009; Accepted 23 April 2009

Recommended by Christa Flueck

Hyponatremia with hyperkalemia in infancy is an uncommon but life-threatening occurrence. In the first weeks of life, this scenario is often associated with aldosterone deficiency due to salt-wasting congenital adrenal hyperplasia. However, alternative diagnoses involving inadequate mineralocorticoid secretion or action must be considered, particularly for infants one month of age or older. We report four infants who presented with profound hyponatremia accompanied by urinary tract infection, ultimately leading to the diagnosis of transient pseudohypoaldosteronism. Our cases provide support for the idea that the renal tubular resistance to aldosterone is due to urinary tract infection itself rather than to underlying urinary tract anomalies typically found in these infants. Awareness of this condition is important so that serum aldosterone, urine sodium, and urine cultures may be obtained immediately in any infant presenting with hyponatremia and hyperkalemia in whom a diagnosis of congenital adrenal hyperplasia was not found. Adequate replacement with intravenous saline and antibiotic therapy is sufficient to correct sodium levels over 24-48 hours.

Copyright (C) 2009 Radha Nandagopal et al. This is an open access article distributed under the Creative Commons Attribution License, which permits unrestricted use, distribution, and reproduction in any medium, provided the original work is properly cited.

\section{Introduction}

Severe hyponatremia with hyperkalemia and dehydration is an uncommon but life-threatening occurrence in infancy. Unless there is clear evidence of gastrointestinal fluid losses, adrenal conditions, particularly congenital adrenal hyperplasia, are high on the differential diagnosis. As neonatal screening for $\mathrm{CAH}$ is now mandatory in most of the United States [1], it becomes increasingly important to consider other, less common, adrenal causes of hyponatremic dehydration. The major diagnoses in this group include congenital adrenal hypoplasia (as well as other causes of hypoadrenalism), isolated aldosterone deficiency, medication administration, and pseudohypoaldosteronism (PHA).

The broad category of PHA includes PHA type 1 (subdivided into primary and transient, or secondary forms) and PHA type 2 (also known as familial hyperkalemic hypertension). Primary PHA type 1 is generally characterized by mutations in the mineralocorticoid receptor or in the genes encoding subunits of the epithelial sodium channel, leading to renal or generalized resistance to aldosterone [2]. Since 1983, there have been several reports of secondary PHA in infancy associated with urinary tract abnormalities, and less commonly, with urinary tract infections (UTI) [3-7]. However, it is our impression that many pediatric specialists, including intensivists, nephrologists, and endocrinologists, remain unfamiliar with this condition and its natural history. We report four infants with hyponatremia and UTI recently diagnosed with PHA at our institution over a two-year period. In three, failure to thrive or weight loss was the presenting feature, and in each the diagnosis of PHA was not immediately suspected; the last of these four patients had two episodes of profound hyponatremia with UTI before the diagnosis was considered. We present these cases to emphasize that the diagnosis of transient pseudohypoaldosteronism should be seriously considered in the dehydrated, febrile, or failing to thrive infant with hyponatremia. 


\section{Methods}

We retrospectively reviewed the medical histories of four children admitted to our center and seen by our pediatric endocrinology service between September 2005 and January 2008. All information was obtained from notes during our evaluations of each patient and complemented with laboratory, imaging, and follow-up data obtained from the electronic medical record. All relevant data, including pertinent laboratory studies and renal anatomical anomalies for each patient, are summarized in Table 1.

\section{Case Reports}

3.1. Patient 1. Patient 1 was a 29 -day-old full-term male transferred to our hospital from an outside facility where he was being investigated for failure to thrive and was found to have severe hyponatremia. Five days prior to admission, he had been evaluated for fussiness by his primary physician and was switched to a high-calorie formula. He developed increased irritability and frequent emesis, and his weight was $3 \%$ less than birth weight. At the outside facility the serum sodium was $124 \mathrm{mmol} / \mathrm{L}$ and serum potassium $8.4 \mathrm{mmol} / \mathrm{L}$. Initial urinary sodium was elevated at $54 \mathrm{mmol} / \mathrm{L}$. He was afebrile when transferred to our Neonatal Intensive Care Unit with the presumptive diagnosis of congenital adrenal hyperplasia, started on intravenous saline and hydrocortisone, oral fludrocortisone, and treated for hyperkalemia. Congenital adrenal hyperplasia was excluded when the 17hydroxyprogesterone level was normal; at that point, a diagnosis of congenital adrenal hypoplasia was considered. Urinalysis revealed pyuria, and urine culture was positive for group B Streptococcus. Voiding cystourethrogram demonstrated left-sided grade 3 to 4 vesicoureteral reflux, and renal sonography demonstrated mild left pelviectasis. Serum sodium and potassium normalized after several days of intravenous fluids and antibiotic therapy. The diagnosis of pseudohypoaldosteronism became apparent when the serum aldosterone level obtained on admission was markedly elevated at $>33.24 \mathrm{nmol} / \mathrm{L}$ (reference range $.083-.44 \mathrm{nmol} / \mathrm{L}$ ) ( $>1200 \mathrm{ng} / \mathrm{dL}$; reference range, $3-16 \mathrm{ng} / \mathrm{dL}$ ). The patient was discharged from the hospital on antibiotic prophylaxis and sodium chloride supplementation. His electrolyte levels remained normal during outpatient follow-up, and the sodium chloride supplementation was discontinued after a month. At age 2 years, the patient underwent successful extravesical ureteral reimplantation and had no postoperative hydronephrosis.

3.2. Patient 2. Patient 2 was a 5-week-old full-term male initially seen by his primary physician for persistently poor weight gain. His birth history was unremarkable. The patient had been breast-feeding and was reported to have normal urine output. Initial sodium in the primary physician's office was $110 \mathrm{mmol} / \mathrm{L}$, and initial potassium was $6.8 \mathrm{mmol} / \mathrm{L}$, prompting immediate concern for salt-wasting congenital adrenal hyperplasia, though the 17-hydroxyprogesterone on the state neonatal screen was normal. At the local emergency room, the child was afebrile, but urinalysis was positive for white blood cells and red blood cells; urine culture subsequently grew Klebsiella oxytoca. The patient was referred to our intensive care unit, where antibiotics and normal saline were provided. Serum aldosterone level was markedly elevated at $21.74 \mathrm{nmol} / \mathrm{L}$ (assay normal $<.25$ $\mathrm{nmol} / \mathrm{L})(785 \mathrm{ng} / \mathrm{dL}$; assay normal $<9 \mathrm{ng} / \mathrm{dL})$. Renal ultrasound demonstrated unilateral hydronephrosis. He was discharged on prophylactic antibiotics, and four months later, the child was diagnosed with stage 1 chronic kidney disease, with marked unilateral pelvocaliectasis and a dilated and tortuous right ureter. His electrolytes remained normal. At age 14 months, he underwent a right nephrectomy. He is no longer on any medications and is doing well.

3.3. Patient 3. Patient 3 was a 7 month-old previously healthy female with an uncomplicated birth history initially seen by her primary physician for weight loss of over $0.45 \mathrm{~kg}$ in a 2-month period. A urinalysis revealed pyuria, and she was treated with amoxicillin; the urine eventually grew Klebsiella pneumoniae. There was no history of fever. Serum electrolytes obtained at the same time revealed hyponatremia and hyperkalemia, so the patient was referred to our facility. Her serum sodium on admission was $116 \mathrm{mmol} / \mathrm{L}$ with a serum potassium $6.7 \mathrm{mmol} / \mathrm{L}$. The serum aldosterone level was markedly elevated at $28.67 \mathrm{nmol} / \mathrm{L}(1035 \mathrm{ng} / \mathrm{dL})$. Renal sonogram revealed unilateral hydronephrosis and hydroureter. In addition to treatment for her urinary tract infection, the patient was sent home on fludrocortisone. Her electrolytes remained normal on followup, and the fludrocortisone was discontinued after 3 weeks. One month later, a furosemide renal scan showed equal function of both kidneys, with no evidence of obstruction. She has, to our knowledge, had no further episodes of urinary tract infections or electrolyte imbalance.

3.4. Patient 4. Patient 4 was a female born at term with a duplicate uterus, duplicated right ureter with hydroureter, aortic coarctation, and a closed myelomeningocele. She was initially admitted with low-grade fever and emesis at age 3.5 months. Initial serum sodium was $103 \mathrm{mmol} / \mathrm{L}$, and potassium was $7.4 \mathrm{mmol} / \mathrm{L}$. Her urinalysis was positive for leukocytes, and urine culture grew Klebsiella oxytoca. Renal sonogram demonstrated resolution of her previous hydronephrosis and hydroureter. She was treated with normal saline and antibiotics, and her UTI and hyponatremia resolved. Serum aldosterone level was not obtained at that admission. She was sent home on prophylactic trimethoprim-sulfamethoxazole. Followup urine culture was negative, but three weeks later the patient had another urine culture, which grew Escherichia coli. At that time, serum sodium was normal. She was readmitted at age 7 months with fever, irritability, and poor oral intake, one month after discontinuation of prophylactic antibiotics. Sodium on admission was $111 \mathrm{mmol} / \mathrm{L}$, potassium $5.7 \mathrm{mmol} / \mathrm{L}$. Urine culture again grew Escherichia coli. DMSA scan revealed an atrophic right upper pole, though this was difficult to distinguish from superimposed pyelonephritis. The day after admission, when her sodium had increased to $127 \mathrm{mmol} / \mathrm{L}$ 
TABLE 1: Characteristics and laboratory data of 4 infants with secondary pseudohypoaldosteronism.

\begin{tabular}{|c|c|c|c|c|c|c|c|c|}
\hline Patient & $\begin{array}{c}\text { Age at } \\
\text { presentation }\end{array}$ & $\begin{array}{l}\text { Serum Na } \\
(\mathrm{mmol} / \mathrm{L})^{1}\end{array}$ & $\begin{array}{c}\text { Serum K } \\
(\mathrm{mmol} / \mathrm{L})^{1}\end{array}$ & $\begin{array}{l}17-\mathrm{OH}-\mathrm{P} \\
(\mathrm{nmol} / \mathrm{L})^{2}\end{array}$ & $\begin{array}{l}\text { Aldosterone } \\
(\mathrm{nmol} / \mathrm{L})^{3}\end{array}$ & $\begin{array}{l}\text { Urine } \mathrm{Na} \\
(\mathrm{mmol} / \mathrm{L})^{4}\end{array}$ & $\begin{array}{l}\text { Urine } \\
\text { microbe }\end{array}$ & Renal imaging ${ }^{5}$ \\
\hline 1 & 29 days & 124 & 8.4 & $2.15(71 \mathrm{ng} / \mathrm{dL})$ & $\begin{array}{l}>33.24 \\
(>1200 \mathrm{ng} / \mathrm{dL})\end{array}$ & 54 & $\begin{array}{l}\text { Group B } \\
\text { Streptococcus }\end{array}$ & $\begin{array}{l}\text { Unilateral grade } 3-4 \\
\text { VUR, mild pelviectasis }\end{array}$ \\
\hline 2 & 5 weeks & 110 & 6.8 & $2.64(87 \mathrm{ng} / \mathrm{dL})$ & $\begin{array}{l}21.74 \\
(785 \mathrm{ng} / \mathrm{dL})\end{array}$ & 12 & $\begin{array}{l}\text { Klebsiella } \\
\text { oxytoca }\end{array}$ & $\begin{array}{l}\text { Unilateral } \\
\text { hydronephrosis }\end{array}$ \\
\hline 3 & 7 months & 116 & 6.7 & $0.69(23 \mathrm{ng} / \mathrm{dL})$ & $\begin{array}{l}28.67 \\
(1035 \mathrm{ng} / \mathrm{dL})\end{array}$ & 7 & $\begin{array}{l}\text { Klebsiella } \\
\text { pneumoniae }\end{array}$ & $\begin{array}{l}\text { Unilateral } \\
\text { hydronephrosis and } \\
\text { hydroureter }\end{array}$ \\
\hline 4 & 3 months & 103 & 7.8 & $4.85(160 \mathrm{ng} / \mathrm{dL})$ & Not obtained & 25 & $\begin{array}{l}\text { Klebsiella } \\
\text { oxytoca }\end{array}$ & $\begin{array}{l}\text { Resolution of previous } \\
\text { hydronephrosis }\end{array}$ \\
\hline 4 (event 2) & 7 months & 111 & 5.6 & Not obtained & $\begin{array}{l}9.62 \\
(347 \mathrm{ng} / \mathrm{dL})\end{array}$ & 21 & Eschericia coli & $\begin{array}{l}\text { Atrophic right upper } \\
\text { pole versus } \\
\text { pyelonephritis }\end{array}$ \\
\hline
\end{tabular}

${ }^{1}$ Serum sodium and potassium values at the time of presentation to clinic or emergency room. ${ }^{2} 17-\mathrm{OH}-\mathrm{P}=$ Serum 17 -alpha hydroxyprogesterone. ${ }^{3}$ Normal range for serum aldosterone: $.083-.44 \mathrm{nmol} / \mathrm{L}(3-16 \mathrm{ng} / \mathrm{dL}) .{ }^{4}$ Urinary sodium was obtained at least one day after the start of antibiotic therapy in all cases expect for Patient 1, in whom the urine sample was obtained the day of antibiotic initiation. ${ }^{5}$ Renal imaging included renal ultrasound, voiding cystourethrogram (VCUG), and in the case of patient 4 2nd visit, DMSA scan.

after IV normal saline, her serum aldosterone was elevated at $9.62 \mathrm{nmol} / \mathrm{L}(347 \mathrm{ng} / \mathrm{dL})$. By the second day the serum sodium was normal, and the patient was discharged home on antibiotic therapy a week later. One month later her electrolytes remained normal and urine culture was negative.

\section{Discussion}

Severe hyponatremia in association with hyperkalemia and dehydration may be seen with congenital adrenal hyperplasia $(\mathrm{CAH})$, congenital adrenal hypoplasia, and other forms of hypoadrenalism, isolated aldosterone deficiency, or pseudohypoaldosteronism. Currently, 47 of 50 states in the United States have required and implemented neonatal screening for $\mathrm{CAH}$ caused by 21-hydroxylase deficiency [8]. As newborn screening for $\mathrm{CAH}$ becomes increasingly common in the United States and in other countries, less common causes of aldosterone deficiency or resistance must be considered in infants brought to medical attention with signs and symptoms of salt-wasting. Congenital adrenal hypoplasia, a rare genetic disorder most commonly caused by mutations in $D A X-1$, responsible for the $\mathrm{X}$-linked form of the disease, causes adrenal insufficiency with profound electrolyte abnormalities; isolated aldosterone deficiency due to aldosterone synthase deficiency can present in a similar manner. While rare in infants and young children, the administration of nephrotoxic medications (e.g., ACE inhibitors, nonsteroidal anti-inflammatory drugs) should also be considered.

In the setting of hyponatremia and hyperkalemia, the key finding of an elevated serum aldosterone strongly suggests the diagnosis of PHA type 1, especially in the first weeks of life. Renal tubular resistance to aldosterone has been previously described in patients with a variety of urinary tract malformations $[4,5,9-14]$. In some cases, the electrolyte imbalance may lead to life-threatening events such as ventricular flutter [15]. However, the condition may be difficult to diagnose promptly, in part because the aldosterone assay is generally sent to a reference laboratory, and results are not available for several days. Thus, the measurement of a urinary sodium level, if possible done prior to sodium replacement and antibiotic therapy, may reveal excessive urinary sodium excretion, suggesting aldosterone deficiency or resistance. Family history, laboratory studies, and the presence of urinary tract malformations may help to differentiate primary genetic PHA type 1 from secondary, or transient, PHA type1.

There remains controversy in the literature regarding the role of microbial infection versus anatomic anomaly in the urinary tract as the underlying pathology leading to mineralocorticoid resistance. Our cases, we believe, support the view that aldosterone resistance may occur solely in the setting of a urinary tract infection, and that the association with urinary tract malformations is due to their high incidence in infants diagnosed with severe urinary tract infections. Four other reports in the literature $[6,13,16$, 17] suggest that severe urinary tract infection itself, and not the combination with an underlying malformation may cause aldosterone resistance. In the case of patient 4 , earlier hydronephrosis associated with meningomyelocoele had resolved, but during her second admission she again presented with a urinary tract infection and evidence of pseudohypoaldosteronism, suggesting that the inciting factor was the presence of severe renal tubular inflammation rather than urinary tract obstruction. One may speculate that the reason this condition is almost exclusively seen in infancy is that the diet of infants is relatively low in sodium. In the face of increased urinary salt loss, infants are not able to compensate by increasing salt intake as older children may be able to do. Our patients represent a slightly older group than those previously reported by some $[3,16,17]$, though 3 of our 4 patients (including the first episode in the case 
of patient 4) presented at age 3.5 months or younger, in agreement with the report by Melzi et al. [5], which suggests that infants 3 months of age or less seem to be at higher risk for this complication of pyelonephritis.

Our patients also demonstrate the transient nature of the aldosterone resistance, distinguishing this condition from the known genetic causes of pseudohypoaldosteronism. The severe inflammation of the kidney itself may contribute to tubular resistance to aldosterone, a phenomenon about which little has been written [17]. All of our patients recovered from their electrolyte imbalances promptly with treatment of their underlying infections and intravenous saline. Although one would expect to see relatively high urine sodium in patients with hyponatremia and aldosterone resistance, three of our four patients had relatively low sodium in urine samples obtained after antibiotic therapy was initiated; this suggests that urinary sodium losses decrease rapidly upon initiation of antibiotic therapy.

The implications of our cases are twofold. First, the diagnosis of transient pseudohypoaldosteronism needs to be a strong consideration in any infant presenting with hyponatremia and hyperkalemia after the first few weeks of life, by which time most cases of congenital adrenal hyperplasia have been diagnosed, either based on newborn screening or a salt-losing crisis. It should be noted that our patients did not present with the typical findings associated with acute urinary tract infection; three of our four patients did not manifest fever as a sign of urinary tract infection, so this condition should be considered even in the afebrile infant with hyponatremia. Urinary sodium, serum aldosterone, and urine cultures need to be ordered without delay, and a renal ultrasound should be obtained if there is pyuria or a positive urine culture. Second, in any particularly ill infant who has evidence of an upper urinary tract infection, serum electrolytes should be checked so that hyponatremia can be detected and treated promptly with intravenous saline.

\section{Acknowledgment}

R. Nandagopal is a pediatric endocrinology fellow and receives salary support from the National Institute of Child Health and Human Development Intramural Program, National Institutes of Health.

\section{References}

[1] A. E. Carroll and S. M. Downs, "Comprehensive cost-utility analysis of newborn screening strategies," Pediatrics, vol. 117, no. 5, pp. S287-S295, 2006.

[2] D. S. Geller, J. Rodriguez-Soriano, A. V. Boado, et al., "Mutations in the mineralocorticoid receptor gene cause autosomal dominant pseudohypoaldosteronism type I," Nature Genetics, vol. 19, no. 3, pp. 279-281, 1998.

[3] V. I. Giapros, A. A. Tsatsoulis, E. A. Drougia, K. D. Kollios, E. C. Siomou, and S. K. Andronikou, "Rare causes of acute hyperkalemia in the 1st week of life. Three case reports," Pediatric Nephrology, vol. 19, no. 9, pp. 1046-1049, 2004.
[4] J. Rodriguez-Soriano, A. Vallo, R. Oliveros, and G. Castillo, "Transient pseudohypoaldosteronism secondary to obstructive uropathy in infancy," The Journal of Pediatrics, vol. 103, no. 3, pp. 375-380, 1983.

[5] M. L. Melzi, S. Guez, G. Sersale, et al., "Acute pyelonephritis as a cause of hyponatremia/hyperkalemia in young infants with urinary tract malformations," The Pediatric Infectious Disease Journal, vol. 14, no. 1, pp. 56-59, 1995.

[6] E. J. Schoen, S. Bhatia, G. T. Ray, W. Clapp, and T. T. To, "Transient pseudohypoaldosteronism with hyponatremiahyperkalemia in infant urinary tract infection," The Journal of Urology, vol. 167, no. 2, part 1, pp. 680-682, 2002.

[7] A. Belot, B. Ranchin, C. Fichtner, et al., "Pseudohypoaldosteronisms, report on a 10-patient series," Nephrology Dialysis Transplantation, vol. 23, no. 5, pp. 1636-1641, 2008.

[8] National Newborn Screening and Genetics Resource Center, http://genes-r-us.uthscsa.edu/resources/genetics/reports.htm.

[9] T. Asano, M. Abe, M. Asai, et al., "Urinary tract malformation and infection with hyperkalemia and decreased fractional excretion of potassium in an infant," Journal of Nippon Medical School, vol. 73, no. 5, pp. 289-291, 2006.

[10] G. Bülchmann, T. Schuster, A. Heger, U. Kuhnle, I. Joppich, and H. Schmidt, "Transient pseudohypoaldosteronism secondary to posterior urethral valves - a case report and review of the literature," European Journal of Pediatric Surgery, vol. 11, no. 4, pp. 277-279, 2001.

[11] T. L. Levin, S. J. Abramson, K. A. Burbige, J. P. Connor, C. Ruzal-Shapiro, and W. E. Berdon, "Salt losing nephropathy simulating congenital adrenal hyperplasia in infants with obstructive uropathy and/or vesicoureteral reflux-value of ultrasonography in diagnosis," Pediatric Radiology, vol. 21, no. 6, pp. 413-415, 1991.

[12] M. R. Perez-Brayfield, J. Gatti, E. Smith, and A. J. Kirsch, "Pseudohypoaldosteronism associated with ureterocele and upper pole moiety obstruction," Urology, vol. 57, no. 6, p. $1178,2001$.

[13] J. Rodriguez-Soriano, A. Vallo, M. J. Quintela, R. Oliveros, and M. Ubetagoyena, "Normokalaemic pseudohypoaldosteronism is present in children with acute pyelopnephritis," Acta Pædiatrica, vol. 81, no. 5, pp. 402-406, 1992.

[14] F. Tütüncüler, H. Günöz, F. Bas, R. Bundak, N. Saka, and O. Neyzi, "Transient pseudohypoaldosteronism in an infant with urinary tract anomaly," Pediatrics International, vol. 46, no. 5, pp. 618-620, 2004.

[15] K.-C. Thies, K. Boos, K. Müller-Deile, W. Ohrdorf, T. Beushausen, and P. Townsend, "Ventricular flutter in a neonate-severe electrolyte imbalance caused by urinary tract infection in the presence of urinary tract malformation," Journal of Emergency Medicine, vol. 18, no. 1, pp. 47-50, 2000.

[16] T. Watanabe, "Hyponatremia and hyperkalemia in infants with acute pyelonephritis," Pediatric Nephrology, vol. 19, no. 3, pp. 361-362, 2004.

[17] M. Gerigk, R. Glanzmann, W. Rascher, and H. E. Gnehm, "Hyponatraemia and hyperkalaemia in acute pyelonephritis without urinary tract anomalies," European Journal of Pediatrics, vol. 154, no. 7, pp. 582-584, 1995. 